\title{
Photothermal techniques: a useful tool to analyze edible oils pureness
}

\begin{abstract}
Vegetable oils have been rising its use in several areas ranging from lubricant additives up to cosmetic industry, therefore, the price of this commodities is rising and the research for new ways to ensure the purity of the oil. By another hand, the photopyroelectric techniques, which are based on the interaction of modulated light, sample, and sensor, have proven to be a useful tool to analyze thermal properties of several kinds of liquids, in several applications. In this work, an introduction to photothermal techniques is given and based on its capabilities the reasons why this kind of techniques can be used for the analysis of samples pureness.
\end{abstract}

Keywords: vegetable oils, photopyroelectric, photothermal techniques, sensors, light
Volume 8 Issue | - 2018

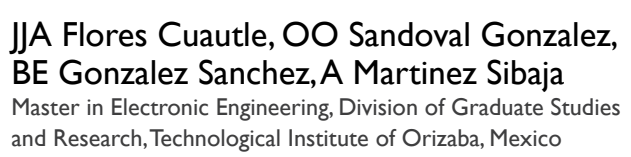

and Research, Technological Institute of Orizaba, Mexico

Correspondence: JJA Flores Cuautle, CONACYT-Master in Electronic Engineering, Division of Graduate Studies and Research, Technological Institute of Orizaba, Orizaba,Veracruz, Mexico,Email jflores_cuautle@hotmail.com

Received: October 12, 2017 | Published: January 29, 2018
Abbreviations: OPC, open photoacoustic cell; TL, thermal lens; ATR-FTIR, attenuated total reflectance-Fourier transform infrared spectroscopy; FTIR, Fourier transform infrared spectroscopy

\section{Introduction}

Photothermal techniques are based on the thermal waves detection, such waves are generated when a modulated light strikes on a sample material, thermal waves then travel through the material, is the material is homogenous then thermal waves propagate freely and, only suffering an attenuation as a function of traveled distance, when the material has defects the waves will suffer not only attenuation but also a dispersion process. The attenuation and dispersion processes are related to the light modulation frequency, sample homogeneity, the sample optical properties and sample thermal properties. Therefore, the thermal waves carry information about thermal and optical properties of the material and its internal structure.

Several setups have been developed and those can be classified according to the used sensor like photopyroelectric, photoacoustic, thermal lens; photopyroelectric techniques are those photothermal setups where a pyroelectric sensor is used. Photopyroelectric techniques are widely used in liquid thermal characterization; this is because simple experimental setups can be enabled. In photopyroelectric techniques there are two main configurations used front and back configurations (Figure 1) (Figure 2).

In these configurations the working principle is the same, a frequency modulated light impinges at the sample or sensor surface changing the luminous energy into thermal energy. Thermal energy is transported through the sample by thermal waves. When the sample structure is uniform the thermal waves suffer a dispersion process when passing across the sample and the sensor, the attenuation rate is closely related with the sample structure, when the structure is not uniform the waves will be not only attenuated but also dispersed. The amplitude and phase of the depend on the sample structure, thermal properties, and modulation frequency, therefore, by performing a frequency sweep it is possible to obtain more information related to the sample structure, therefore, the thermal properties are indirectly carried information about a possible alteration in the sample chemical composition.

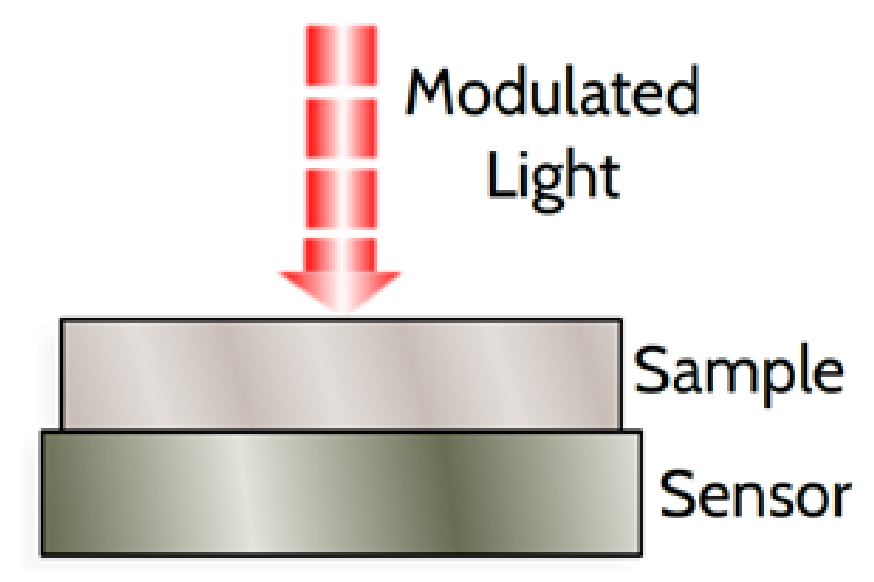

Figure I Photopyroelectric front configuration.

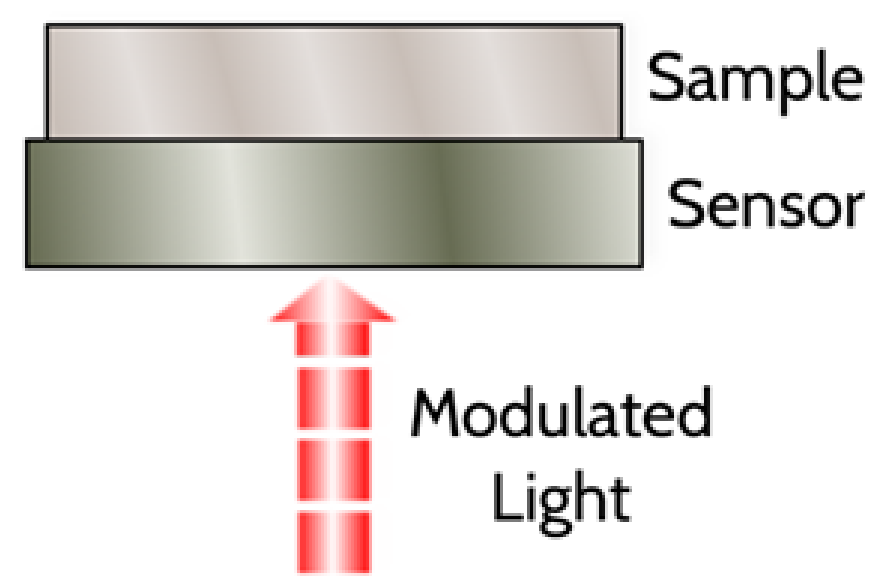

Figure 2 Photopyroelectric back configuration. 
Photopyroelectric techniques have been used by several researchers in several oils studies, ${ }^{1-6}$ among a wide variety of techniques that can be used for studying this kind of samples, photothermal techniques stand out because of the variety of information that can provide. The reasons for studying vegetable oils are because of the wide variety of uses that can be given to these oils, applications in industry as lubricants, ${ }^{1,7}$ biofuels, ${ }^{8}$ cosmetic, ${ }^{9}$ chemical processes ${ }^{10-12}$ and in a food industry.

Several applications have proved the capabilities of the photothermal techniques to explore very low concentrations of solute in a solution, for instance, the most frequent examples are metal nanoparticles in nanofluids, in this sense, concentrations as low as $1 * 10^{-5} \%$ w have been detected ${ }^{13}$ or $0.5 \%$ x for another type of nanofluids. ${ }^{14}$

\section{Photothermal techniques in edible oils}

Among studied oils, those oils useful for food industry rise interest because food commodities are always a necessity. Balderas and coworkers have analyzed edible oils and conclude that it is not possible to distinguish between different oils ${ }^{15}$ despite that, there is experimental evidence from the same group that supports the possibility to distinguish between commercial and extra-virgin olive oil.

Olive oil studies stands out among vegetable oils, ${ }^{5,6}$ this is mainly for the economic reasons, Balderas et al., ${ }^{3}$ made a full thermal characterization obtaining thermal diffusivity, thermal effusivity, and thermal conductivity with values of $0.978^{*} 10^{-7} \mathrm{~ms}^{-2}, 0.051 * 10^{4} \mathrm{Ws}^{1 / 2} \mathrm{~m}^{-}$ ${ }^{2} \mathrm{~K}^{-1}$, and $0.16 \mathrm{Wm}^{-1} \mathrm{~K}^{-1}$ respectively for commercial oil whereas for extra-virgin olive oil the values were $0.983 * 10^{-7} \mathrm{~ms}^{-2}, 0.048 * 10^{4} \mathrm{Ws}^{1 / 2} \mathrm{~m}$ ${ }^{2} \mathrm{~K}^{-1}$, and $0.15 \mathrm{Wm}^{-1} \mathrm{~K}^{-1}$, as it can be seen, the differences among thermal properties range from $0.5 \%$ for thermal diffusivity till $7 \%$ for thermal conductivity, the sample purity makes a change in thermal parameters, in this way a discriminant in oil integrity can be obtained from thermal properties studies.

Another example where the role of the thermal properties can be seen is the coffee, in this case, the quality, as well as the organic agriculture, are two key parameters which determine the market price, in this case, Bedoya and coworkers performed studies on coffee essential oil, especially in the thermal effusivity, they found values of $604-610 \mathrm{Ws}^{1 / 2} \mathrm{~m}^{-2} \mathrm{~K}^{-1}$ for conventional coffee and $592-597 \mathrm{Ws}^{1 / 2} \mathrm{~m}^{-2} \mathrm{~K}^{-1}$ for organic oil, ${ }^{2}$ which are differences up to $3 \%$ between the thermal effusivity of conventional coffee oil and organic coffee oil.

Not only the thermal effusivity shows differences between organic and conventional coffee oil, the photoacoustic spectroscopy, especially the mid-infrared (FTIR-PAS) was used to identify the functional groups from the FTIR-PAS spectra. These results open the window to have a discrimination method for separating organic from conventional coffee.

Citrus oils are composed by a complex mixture of chemical groups, in addition, the final chemical composition depends strongly on the soil, harvest time and the process used to extract the oils, therefore, is it hardly complicated to determine in a precise way quality differences among these oils. A study made on lemon and orange oils shows $0.142 \mathrm{Wm}^{-1} \mathrm{~K}^{-1}$ and $0.136 \mathrm{Wm}^{-1} \mathrm{~K}^{-1}$ values of thermal conductivity, ${ }^{16}$ those values are the result of combining the Open photoacoustic Cell (OPC) and the Thermal Lens (TL).

The results on citrus oil thermal parameters show a difference, not only in thermal conductivity but also in thermal diffusivity, in addition, UV-vis spectroscopy combined with Attenuated Total Reflectance-Fourier Transform Infrared Spectroscopy (ATR-FTIR) were used for Orea and coworkers to reveal the chemical composition for this type of oils. ${ }^{16}$ The obtained results confirm the values obtained by Balderas ${ }^{3}$ and also reveal that these thermal parameters can be used as discriminant criteria to distinguish between these types of oils.

Several other examples can be found in the literature, like avocado oil with thermal effusivity reported values ${ }^{4,5}$ for this sample there is a difference in the reports values for different authors up to $12 \%$ this can be the result of the differences in samples, but, in this especial case, no conclusion can be reached because the authors do not report the brand or the name of the sample supplier, maize oil thermal diffusivity, grape seed oil thermal diffusivity among others are other examples found in the literature, from the available literature of edible oils thermal properties it is possible to say that, despite thermal properties of edible oils are similar, these properties can be used as a criteria to discern about sample pureness.

\section{Conclusion}

Photothermal techniques are well-established techniques especially for liquids thermal characterization, as reviewed literature shows, these techniques provide information on thermal parameters which can be used as discriminant about sample purity, it is important to point out that despite these techniques provides useful information; careful use of this inforxtmation must be taken. Some authors claim thermal parameters are a criterion for discrimination, but there are those who say that due to the thermal parameters are so close to different oils establish a clear difference is a handicap.

The importance of study thermal parameters in order to find new methods to get knowledge about oils pureness is showed by the results already available in the literature.

\section{Acknowledgements}

None.

\section{Conflict of interest}

The author declares no conflict of interest.

\section{References}

1. Gallardo-Hernández EA, Lara-Hernández G, Nieto-Camacho F, et al. Thermal and Tribological Properties of Jatropha Oil as Additive in Commercial Oil. International Journal of Thermophysics. 2017;38(4):54

2. Bedoya A, Gordillo-Delgadoa F, Cruz-Santillanaa YE, et al. Thermal effusivity measurement of conventional and organic coffee oils via photopyroelectric technique. Food Research International. 2017;102:419424.

3. López-Muñoz GA, Balderas-López JA. Photothermal characterization of citrus essential oils and their derivatives. Thermochimica Acta. 2014;579:40-44

4. Lara-Hernández G, Suaste-Gómez E, Cruz-Orea A, et al. Thermal Characterization of Edible Oils by Using Photopyroelectric Technique. International Journal of Thermophysics. 2013;34(5):962-971.

5. Cervantes-Espinosa LM, de L Castillo-Alvarado F, Lara-Hernández G, et al. Thermal Effusivity of Vegetable Oils Obtained by a Photothermal Technique. International Journal of Thermophysics. 2013;35(910):1940-1945.

6. Balderas-Lopez J, Monsivais Alvarado G, Galvez Coyt A, et al. Thermal characterization of vegetable oils by means of photoacoustic techniques. Revista Mexicana de Fisica. 2013;59(1):168-172. 
7. Shahabuddin MT, Masjuki HH, Kalam MA, et al. Comparative tribological investigation of bio-lubricant formulated from a non-edible oil source (Jatropha oil). Industrial Crops and Products. 2013;47:323-330.

8. Martini N, JS Schell. Plant Oils as Fuels: Present State of Science and Future Developments 2012. Berlin: Springer; 2012.

9. Ogunniyi DS. Castor oil: A vital industrial raw material. Bioresour Technol. 2006;97(9):1086-1091.

10. Antolín G, Tinautb FV, Briceñoc Y, et al. Optimisation of biodiesel production by sunflower oil transesterification. Bioresource Technology. 2002;83(2):111-114.

11. Crabbe E, Cirilo Nolasco-Hipolito, Genta Kobayashi, et al. Biodiesel production from crude palm oil and evaluation of butanol extraction and fuel properties. Process Biochemistry. 2001;37(1):65-71.
12. Linko YY, Lämsä M, Wu X, et al. Biodegradable products by lipase biocatalysis. J Biotechnol. 1998;66(1):41-50.

13. Kouyaté M, Flores-Cuautle JJA, Slenders E, et al. Study of Thermophysical Properties of Silver Nanofluids by ISS-HD, Hot Ball, and IPPE Techniques. International Journal of Thermophysics. 2015;36(10 11):3211-3221.

14. Slenders E. Photothermal characterization of nanofluids. Departement Natuurkunde \& Sterrenkunde, Katholieke Universiteit Leuven; 2013.

15. Balderas-Lopez JA, Acosta-Avalos D, Alvarado JJ, et al. Photoacoustic measurements of transparent liquid samples: thermal effusivity. Measurement Science and Technology. 1995;6(8):1163.

16. Carbajal-Valdez R, Jiménez-Pérez JL, Cruz-Orea A, et al. Thermal properties of centrifuged oils measured by alternative photothermal techniques. Thermochimica Acta. 2017;657:66-71. 